\title{
MICROEMPREENDEDORINDIVIDUAL COMO INSTRUMENTO DE DESENVOLVIMENTO SOCIOECONÔMICO E EMPRESARIAL BRASILEIRO
}

\section{INDIVIDUAL MICROEMPREENDEDORAS A BRAZILIAN SOCIOECONOMIC AND BUSINESS INSTRUMENT}

\author{
Raiza Oliveira do Carmo Mizael $^{1}$
}

Estudante do Curso de Direito

Centro Universitário de Barra Mansa - Rio de Janeiro (RJ)

RESUMO: 0 artigo apresenta dados relativos aos resultados do programa de formalização do microempreendedor no Brasil e analisar esta figura jurídica, no Brasil, deu certo ou não. Justifica-se este ensaio dada a importância de analisar se há ou não eficiência na implantação do Programa do Governo Federal - Portal do Empreendedor após intensa campanha publicitária do Governo Federal visando integrar os microempreendedores regulares na sociedade brasileira, o que é o seu objetivo geral. Os objetivos especiais são os de: (I) caracterizar a figura do microempreendor; (II) entender o funcionamento do SIMEI; e (III) expor os resultados do Programa em análise. A metodologia de pesquisa tem as seguintes abordagens: (I) teórica - revisão bibliográfica com consultas em livros, revistas, cartilhas; (II) dados secundários - com investigação de sites oficiais informativos sobre o tema; e (III) investigativa quantitativa - para alcançar os objetivos propostos.

Palavras-chave: Microempreendedor desenvolvimento socioeconômico. SIMEI Abstract:This research report aims to present empirical data on the results of the microentrepreneurs formalization Program in Brazil and analyze this legal form in Brazil, worked or not. This test is justified given the importance of analyzing whether or not there efficiency in the Program implementation - Microentrepreneur Portal - after intensive advertising campaign to integrate regular microentrepreneurs in Brazilian society, what is your overall goal. The special goals are: (I) characterizing the microempreendor (II) understand the SIMEI operation and reito - NUPED. Pesquisa financiada pelo UBM na modalidade auxílio financeiro. E-mail: ra-mizael@hotmail.com. 
(III) display the results of the analysis in program. The research methodology has three approaches: (I) theoretical - bibliographic queries in books, magazines, booklets, (II) secondary data - with research sites official information on the subject, and (III) quantitative investigative - to achieve the proposed objectives.

Key words: Microentrepreneurs. Development socioeconomic.SIMEI.

\section{INTRODUÇÃO}

Os países formadores deste continente do hemisfério sul, por força da história comum de uma colonização "usurpadora" e de terem todos passados por regimes ditatoriais possuem algumas características econômicas comuns, como a prática de atividade empresária irregular sem sanção cominada, por ser necessária a subsistência da população o exercício da atividade empresária independentemente de qualquer formalização.

0 presente relatório de pesquisa visa apresentar os dados relativos aos resultados do programa de formalização do microempreendedor no Brasil e analisar esta figura jurídica, para verificar se é possível utilizá-la em qualquer um dos países integrantes da América Latina.

Sendo assim, justifica-se este ensaio dada a importância de verificar se há ou não eficiência na implantação do Programa do Governo Federal - Portal do Empreendedor após intensa campanha publicitária do Governo Federal visando integrar os microempreendedores regulares na sociedade brasileira.

0 objetivo geral foi o de verificar quais são os resultados relativos ao enquadramento no SIMEI - Simples Nacional do microempreendedor individual - durante os anos de 2010 a 2013, quando ocorre intensa campanha do Governo Federal visando integrar os microempreendedores regulares na sociedade brasileira. Os objetivos especiais são os de: (I) caracterizar a figura do microempreendor; (II) entender o funcionamento do SIMEI; e (III) analisar os dados e expor os resultados do Programa em análise.

A metodologia de pesquisa tem as seguintes abordagens: (I) teórica - revisão bibliográfica com consultas em livros, revistas, cartilhas; (II) dados secundários com investigação de sites oficiais informativos sobre o tema; e (III) investigativa quantitativa - para alcançar o objetivo geral proposto. 


\section{Caracterização do Microempreendedor Individual}

Considera-se Microempreendedor Individual - MEl o empresário a que se refere o art. 966 da Lei 10.406/2002 (Código Civil), o empresário que tenha auferido receita bruta acumulada nos anos-calendário anterior e em curso de até $\mathrm{R} \$$ $60.000,00$, ou seu limite proporcional se estiver no ano de início de atividade.

Ademais deve atender aos seguintes requisitos:

- exercer tão-somente as atividades constantes do Anexo XIII da Resolução CGSN 94/2011;

- possuir um únicoestabelecimento;

- não participar de outra empresa como titular, sócio ou administrador; e

- não contratar mais de um empregado, observado o disposto no art. 96 da Resolução CGSN 94/2011.

Verificados se foram cumpridos os requisitos acima o empresário interessado no enquadramento para obter as vantagens relativas a formalização e as garantias sociais deve cadastrar-se no SIMEI - Sistema do Microempreendedor Individual.

\section{SIMEI - Simples Nacional do Microempreendedor Individual}

SIMEl é o sistema de recolhimento em valores fixos mensais dos tributos abrangidos pelo Simples Nacional, devidos pelo Microempreendedor Individual, conforme previsto no artigo 18-A da Lei Complementar $n^{\circ} 123$, de 14 de dezembro de 2006, após todas as alterações posteriores a sua promulgação.

A inscrição como Microempreendedor Individual e, a consequente opção pelo SIMEI, pode se realizar de duas formas:

- Os novos empreendedores podem fazê-lo a qualquer tempo por meio do Portal do Empreendedor que se encontra na Internet; ou

- os empreendedores já formalizados, em janeiro de cada ano, podem se cadastrar no Portal do Simples Nacional.

As obrigações principais do Microempreendedor Individual quando enquadrados no SIMEI são as de: 
- imprimir e quitar mensalmente o documento de arrecadação do Simples Nacional-DAS;

- preencher, mensalmente, e manter sob sua guarda o "Relatório Mensal de Receitas Brutas" (anexo XII da Resolução CGSN 94/2011);

- apresentar, até 31 de maio de cada ano, a Declaração Anual do Simples Nacional do Microempreendedor Indivudal (DASN-SIMEI).

O microempreendedor estará dispensado de emitir nota fiscal para consumidor pessoa física, porém, estará obrigado à emissão quando o destinatário da mercadoria ou serviço for cadastrado no CNPJ, salvo quando esse destinatário emitir nota fiscal de entrada pra garantir a formalidade da operação.

Para simplificar ainda mais, o microempreendedor fica dispensado da escrituração dos livros fiscais e contábeis, da Declaração Eletrônica de Serviços e da emissão da Nota Fiscal Eletrônica (NF-e).

Os valores pagos mensalmente pelo Microempreendedor que negocia produtos e não serviços são:

- R\$ 5,00 de ISS, caso seja contribuinte deste imposto;

- $\mathrm{R} \$ 1,00$ de ICMS, caso seja contribuinte deste imposto e

- R\$33,90 a título de contribuição para a Seguridade Social relativa à pessoa do empresário ( $5 \%$ do limite mínimo mensal do salário de contribuição).

Em resumo, o SIMEI é um sistema de pagamento de tributos unificados em valores fixos mensais que permite aos microempreendedores obterem sua regularização ao mesmo tempo em que auxilia as relações sociais em sociedade e o Estado.

\section{Relatório, análise e resultados dos dados secundários da pesquisa com investigação de sites oficiais informativos sobre o tema.}

Primeiramente, salienta-se a importância de verificar se há ou não eficiência na implantação do Programa do Governo Federal - Portal do Empreendedor após intensa campanha publicitária do Governo Federal visando integrar os microempreendedores regulares na sociedade brasileira. Pois, o objetivo geral deste relatório de pesquisa é o de quantificar quais são os resultados relativos ao enqua- 
dramento no SIMEI - Simples Nacional do microempreendedor individual - durante os anos de 2010 a 2013.

Primeiramente, far-se-ão as análises quantitativas dos dados apresentados nas tabelas abaixo, para depois as apresentar.

Como primeiro elemento de quantificação sobre o tema analisado buscou-se no site da Receita Federal as tabelas 1 e 2, que tratam do panorama dos optantes do SIMEI por Estados, para constatar-se se a inclusão dos microempreendedores no sistema empresarial brasileiro formal teve qualquer incremento de 2010 a 2013.

A verificação dos números em análise quantitativa das tabelas abaixo serão utilizadas como comprovação se toda a campanha publicitária realizada pelo Governo Federal durante os anos de 2010 e 2013, foi eficiente ou não para incrementar os número de optantes do SIMEI, que é a hipótese investigada neste relatório de pesquisa.

\begin{tabular}{|c|c|}
\hline \multicolumn{2}{|c|}{ Tabela 1: Empresas optantes pelo SIMEI em 01/01/2010 } \\
\hline UF & TOTAL DE OPTANTES \\
\hline AC & 1 \\
\hline BA & 3 \\
\hline CE & 1.331 \\
\hline DF & 2.700 \\
\hline ES & 2.509 \\
\hline GO & 9 \\
\hline MG & 9.262 \\
\hline PB & 1 \\
\hline PI & 1 \\
\hline PR & 3.461 \\
\hline RJ & 6.852 \\
\hline RN & 3 \\
\hline RO & 2 \\
\hline SC & 3.910 \\
\hline SP & 1.706 \\
\hline Total Geral & 13.597 \\
\hline
\end{tabular}

Legenda: A tabela apresenta os números relativos ao ano de 2010. Observa-se que em 2011, apenas 15 Estados dos 27 da federação brasileira aderiram ao Programa do Governo - Portal do Empreendedor, elaborada a partir da análise de dados do ano de 2010, extraídos do site da Receita Federal. Disponível em: <http://www8. receita.fazenda.gov.br/SimplesNacional/Aplicacoes/ATBHE/estatisticas.app/Estatisticas/SimeiPorUF.aspx?ano=2010\&evento=I501>Acesso em: 02 de mai. 2013. 


\section{RAIZA OLIVEIRA DO CARMO MIZAEL}

\begin{tabular}{|c|c|}
\hline UF & TOTAL DE OPTANTES \\
\hline $\mathrm{AC}$ & 8.977 \\
\hline $\mathrm{AL}$ & 35.008 \\
\hline$A M$ & 28.728 \\
\hline$A P$ & 7.721 \\
\hline BA & 190.820 \\
\hline CE & 78.187 \\
\hline DF & 49.823 \\
\hline ES & 68.004 \\
\hline GO & 96.563 \\
\hline MA & 37.512 \\
\hline MG & 267.260 \\
\hline MS & 42.281 \\
\hline MT & 52.080 \\
\hline PA & 73.048 \\
\hline PB & 35.416 \\
\hline $\mathrm{PE}$ & 89.581 \\
\hline $\mathrm{PI}$ & 22.929 \\
\hline PR & 132.591 \\
\hline RJ & 325.841 \\
\hline RN & 36.496 \\
\hline RO & 21.087 \\
\hline RR & 5.748 \\
\hline RS & 146.834 \\
\hline SC & 85.827 \\
\hline $\mathrm{SE}$ & 19.055 \\
\hline SP & 633.305 \\
\hline TO & 21.638 \\
\hline Total Geral & 2.612 .360 \\
\hline
\end{tabular}

Legenda: A Tabela acima apresenta os números relativos ao ano de 2013. Observa-se que os 27 Estados da federação brasileira aderiram ao Programa do Governo - Portal do Empreendedor. Elaborada a partir da análise de dados do ano de 2013, extraídos do site da Receita Federal. Disponível em:<http://www8. receita.fazenda.gov.br/SimplesNacional/Aplicacoes/ATBHE/estatisticas.app/Estatisticas/SimeiPorUF.asp x?ano=2010\&evento=I501>Acesso em: 02 de mai. 2013. 


\section{Tabela 3: Motivos para o desenquadramento no SIMEI}

\begin{tabular}{|l|r|}
\hline \multicolumn{1}{|c|}{ MOTIVO DA EXCLUSÄO } & TOTAL \\
\hline E534 - Desenquadramento do SIMEI por opção. & 268 \\
\hline $\begin{array}{l}\text { E536 - Exclusão por comunicação do contribuinte - Excesso de receita } \\
\text { bruta fora do ano calendário de início de atividades }\end{array}$ & 2 \\
\hline E537 - Exclusão por comunicação do contribuinte - Débitos & 3 \\
\hline $\begin{array}{l}\text { E538 - Desenquadramento do SIMEl por comunicação do contribuinte - } \\
\text { Natureza jurídica vedada. }\end{array}$ & 2 \\
\hline $\begin{array}{l}\text { E539 - Desenquadramento do SIMEl por comunicação do contribuinte - } \\
\text { Atividade econômica vedada. }\end{array}$ & 14 \\
\hline $\begin{array}{l}\text { E543 - Exclusão por comunicação do contribuinte - Participa no capital } \\
\text { pessoa física inscrita como empresário ou sócia de outra PJ beneficiada } \\
\text { pela LC no 123, tendo a RB global ultrapassado o limite. }\end{array}$ & 2 \\
\hline $\begin{array}{l}\text { E544 - Exclusão por comunicação do contribuinte - Titular ou sócio com } \\
\text { participação superior a 10\% no capital de outra Pessoa Jurídica, não } \\
\text { beneficiada pela LC no 123, tendo a RB global ultrapassado o limite. }\end{array}$ & 2 \\
\hline $\begin{array}{l}\text { E545 - Exclusão por comunicação do contribuinte - Sócio ou titular é } \\
\text { administrador de outra Pessoa Jurídica com fins lucrativos }\end{array}$ & 23 \\
\hline $\begin{array}{l}\text { E546 - Exclusão por comunicação do contribuinte - Participação de outra } \\
\text { Pessoa Jurídica no capital da empresa optante }\end{array}$ & 166 \\
\hline $\begin{array}{l}\text { E551 - Desenquadramento do SIMEl - Desenquadramento por decisão } \\
\text { administrativa. }\end{array}$ & 792 \\
\hline $\begin{array}{l}\text { E552 - Desenquadramento do SIMEl - Desenquadramento por medida } \\
\text { judicial. }\end{array}$ & 22.680 \\
\hline $\begin{array}{l}\text { E556 - Exclusão de Ofício - Débitos. } \\
\text { E590 - Exclusão de Ofício - Pessoa Jurídica Baixada. }\end{array}$ & 2 \\
\hline $\begin{array}{l}\text { E598 - Exclusão de Ofício - Ausência de regularização da inscrição } \\
\text { Total Geral }\end{array}$ & 2 \\
\hline
\end{tabular}

Legenda: Lista dos motivos para o desenquadramento no SIMEI estabelecido pela legislação vigente e o número de desenquadramentos no Brasil. Fonte: Dados extraídos do site da Receita Federal. Disponível em:<http://www8.receita.fazenda.gov.br/SimplesNacional/Aplicacoes/ATBHE/estatisticas.app/Estatisticas/SimeiPorUF.aspx?ano=2010\&evento=I501>Acesso em: 10 de mai. 2013. 
Com esta análise quantitativa, comprova-se, então, que os resultados relativos ao enquadramento no SIMEI - Simples Nacional do microempreendedor individual - durante os anos de 2010 a 2013, quando ocorreu uma intensa campanha do Governo Federal visando integrar os microempreendedores regulares na atividade empresarial regular na sociedade brasileira são positivos, bem como alcançou-se os objetivos propostos neste relatório de pesquisa por meio da apresentação dos resultados acima aludidos.

\section{CONSIDERAÇÕES FINAIS}

Percebe-se com as investigações que foram realizadas que o Programa do Governo Federal - Portal do Empreendedor - representa um anseio da população brasileira, particularmente os empresários individuais que se encontravam sem qualquer proteção jurídica ou social até a data da promulgação da legislação competente que implantou o SIMEI.

Comprova-se, portanto, que as vantagens da nova legislação para os microempreendedores representam um avanço econômico e social que todos os países formadores deste continente do hemisfério sul, deveriam utilizar como referência já que a história comum da colonização "usurpadora" e os regimes ditatoriais impõem aos países da América Latina características econômicas comuns, como a prática de atividade empresária irregular sem sanção cominada, por ser necessária a subsistência da população latino americana, o exercício da atividade empresária independentemente de qualquer formalização.

Agora, no Brasil, tais cidadãos, denominados microempreendesores, recebem as garantias sociais advindas do cadastro no Instituto Nacional de Seguridade Social - INSS que representam uma segurança em diversas situações como nas de: maternidade, acidente, doença, incapacidade, invalidez, prisão, idade avançada, tempo de contribuição, morte, além de reabilitação profissional.

Além da Isenção das taxas de registros e alterações contratuais realizadas nas Juntas Comerciais e em outros órgãos públicos. E, quando da emissão de notas fiscais, somente serão necessárias as de vendas de mercadorias e prestação de serviços efetuados para outras pessoas jurídicas (empresas). Também, desobriga-se a contabilidade do microempreendimento, bem como a declaração de renda de pessoa jurídica e ao cumprimento de várias obrigações próprias, acessórias das outras empresas. 
Terão acesso às linhas de créditos para financiamento específicos, compatíveis com a condição de pequenos empreendedores, ou seja, as taxas serão reduzidas.

Acesso ao mercado através das suas próprias empresas, adquirindo mercadorias de grandes empresas atacadistas por preços menores e acompanhadas de nota fiscal.

Pagarão tão somente uma contribuição que varia entre $\mathrm{R} \$ 52,15$ a $\mathrm{R} \$ 57,15$, incluindo todos os impostos, taxas e contribuições e possuirão regularidade fiscal, mediante comprovação das aquisições e vendas de mercadorias com notas fiscais. Importante ressaltar que irá se evitar perda de mercadorias por falta de documentação legal ou multa pela inexistência de notas fiscais na saída das mercadorias.

Não haverá mais tanto risco nas reclamatórias trabalhistas, já que o dinheiro destinado a taxas e tributos será destinado à regular contratação dos empregados.

Terão comprovação de renda através da declaração extraída de sua renda devidamente regularizada. $\mathrm{E}$, terão a tranquilidade de estar exercendo suas atividades de forma legal, sem a necessidade de burlar a fiscalização e com expectativa e apoio governamental e institucional e das instituições financeiras.

\section{REFERÊNCIAS}

BRASIL. LC $n^{\circ} .128 / 08$, de 19 de dezembro de 2008. Altera a LC $n^{\circ} 123$, de 14 de dezembro de 2006, altera as Leis nos 8.212, de 24 de julho de 1991, 8.213, de 24 de julho de 1991, 10.406, de 10 de janeiro de 2002 - Código Civil, 8.029, de 12 de abril de 1990, e dá outras providências. Diário Oficial da União,Poder Executivo, Brasília, DF, 22.12.2008.

. LC n. 139, de 10 de novembro de 2011. Altera dispositivos da LC $n^{\circ} 123$, de 14 de dezembro de 2006. Disponível em: <http://www.planalto.gov.br/ccivil_03/Leis/LCP/ Lcp123.htm>Acesso em: 20 mar. 2013.

- Câmara dos Deputados. Microempreendedor Individual. Brasília: Câmara, 2010. Disponível em: <http://bd.camara.gov.br/bd/> citado no site do SEBRAE<www.sebrae.com.br>. Acesso em:8 mar. 2013. 
Portal do Empreendedor. Obtenção de alvará de funcionamento definitivo para o MEl. Disponível em: <http://www.portaldoempreendedor.gov.br>. Acesso em: 10 ago. 2013.

DORNELAS, José Carlos de Assis. Empreendedorismo: transformando idéias em negócios. Rio de Janeiro: Campus, 2001.

FÉRES, Marcelo Andrade. Estabelecimento empresarial: trespasse e efeitos obrigacionais. São Paulo: Saraiva. 2007.

FERNANDES, Jean Carlos; MACIEL, Luciana Botelho; MACIEL, Henrique Matheus Mariani. Microempreendedor Individual (MEI):vantagens e desvantagens do novo sistema. Disponível em: <http://www.biblioteca.sebrae.com.br/bds/BDS. nsf/>. Acesso em: 05 mar. 2013.

GOMES, Josemeire Alves et al. O retrato do empreendedor informal.XXV Encontro Nacional de Engenharia de Produção. Porto Alegre, 29 de outubro a 01 de novembro de 2005.

PIETROBON, V.; OKAMOTO, P. Cartilha do Empreendedor Individual. Copyright. FENACON. 2009.

SEBRAE, Serviço Brasileiro de Apoio às Micro e Pequenas Empresas. Manual Empreendedor Individual. 1. ed. Brasília: SEBRAE, maio de 2009. Disponível em: <www.sebrae.com.br>. Acesso em: 18 mar. 2013.

. Serviço Brasileiro de Apoio às Micro e Pequenas Empresas.Cartilha do Empreendedor. Disponível em: <www.sebrae.com.br>.Acesso em: 20 abr. 2013. SIMÃO FILHO, Adalberto. Direito Empresarial. Direito Societário Contemporâneo. São Paulo: Saraiva, 2012.

SOUZA, Dayanne Marlene. Os principais benefícios proporcionados ao trabalhador informal para formalização através do microempreendedor individual. Disponível em: <http://tcc.bu.ufsc.br/Contabeis294059>. Acesso em: 10 mai. 2013. 